\title{
Papillary thyroid microcarcinoma: how deal with this epidemic?
}

\section{Editorial}

Papillary thyroid microcarcinoma (PTmC), encompassing any papillary thyroid carcinoma (PTC) measuring $10 \mathrm{~mm}$ or below in greatest dimension. In the last four decades, trend incidence of PTC, especially the microtumors, is increasing in several epidemiological studies around the world. ${ }^{1-3}$ Microcarcinomas are usually an incidental finding, increasing found on imaging or on histology of thyroidectomy specimens. The term incidental refers to a tumour that is not the target lesion and is found on histological examination of a thyroid removed for another reason, for instance nodular goitre. These lesions nearly always are of papillary form.

Despite its high incidence and prevalence, PTmC rarely cause of death. Most patients with these lesions have an excellent prognosis, since these tumours follow a highly indolent course they have been denoted as low risk thyroid cancer, ${ }^{4}$ however, owing to uncertainty about definition, epidemiology, and management of these kind of cancers, many patients receive similar care to that for more aggressive thyroid cancers. The acronym VOMIT which stands for Victims of Modern Imaging Technologies, describes this situation. ${ }^{5}$ New evidence has led to a better understanding of this condition and may herald a revolution in its management.

Review of several studies revealed the clinical and histopathological characteristics of the PTmC, $28 \%$ of patients had multifocal tumours, $18 \%$ bilateral tumours, $12.5 \%$ extratiroidal invasion, $10.7 \%$ lymph node extension, $3.3 \%$ distant metastasis, $4.2 \%$ tumour recurrence and only $0.2 \%$ mortality related with the PTmC. ${ }^{6}$

Information on the spontaneous evolution of PTmC comes from the classic studies by Ito et al., ${ }^{7,8}$ which include patients with no incidental PTmC, attended in the period 1993-2011. All cases diagnosed by fine needle aspiration biopsy (FNAB) guide by echography. Patients with lymph node invasion, those with tumour located adjacent to trachea and those with nodules having histopathology features of high-grade malignancy were excluded. At 10-years of followed-up, from the 1235 patients included in the study, $8 \%$ of patients showed tumour enlargement by $3 \mathrm{~mm}$ or more, $6.8 \%$ of patients tumour size become greater than $10 \mathrm{~mm}$ and only $3.8 \%$ of patients showed novel appearance of lymph-node invasion.

Regarding to post surgical outcome of PTmC, the experience of the Mayo Clinic is very demonstrative. Hay et al., ${ }^{9}$ studied longitudinally 900 cases of PTmC attended in the mentioned institution from 1945 to 2004. They observed that all-cause survival of these patients is similar as expected survival of persons of like age and sex based. More than $99 \%$ of patients had not distant spread or mortality. Only $0.3 \%$ cases died related to PTmC. The cumulative risks of tumour recurrence development at any site were $5.5 \%$ at 20 years of followed-up. Thus in the management of the PTmC the problem is the tumour recurrence.

Several groups of researchers have tried to established what clinical or histopatological characteristics of the PTmC determinates the outcome of these patients., ${ }^{40-14}$ They evaluated the prognosis

\author{
Volume I Issue I - 2015
}

\author{
Ricardo V Garcia-Mayor \\ South Galicia Biomedical Foundation, University Hospital of \\ Vigo, Spain
}

\begin{abstract}
Correspondence: Ricardo V Garcia-Mayor, South Galicia Biomedical Foundation, University Hospital of Vigo, PO, Box 1691, Plaza de Compostela 3, 3620 I Vigo, Spain,
\end{abstract} Email ricardo.garcia.mayor@sergas.es

Received: January 06, 2015 | Published: January 08, 2015

value of: age, gender, tumour size, incidental tumour, multifocal tumour, lymph-node extension, and molecular characteristics such as BRAF mutation. In resume, the outcome of PTmC showed the more consistent association with lymph-node invasion and incidental tumours, being the first predictor of recurrence, while the second is predictor of a very good prognosis.

The fact that the majority of PTmC have very good prognosis promote that several authors ${ }^{15-17}$ and the guidelines from different institutions recommend conservative treatment for these tumours. ${ }^{18-22}$

Based on the aforementioned information, the appropriate treatment for unifocal PTmC without other risk factors, mainly lymph-node involvement, should be lobectomy, with the option of observation without surgery. Neither adjuvant radioiodine therapy nor use of suppressive doses of L-Tiroxine, in cases required this treatment, are recommend. Respect to the follow-up, would be based on image techniques, mainly ultrasonography during 5 years, with the option for these patients of no further follow-up for cancer and can be discharged to the care of their general practitioner. ${ }^{23}$

\section{Acknowledgments}

None.

\section{Conflict of interest}

The author declares there is no conflict of interest.

\section{References}

1. Davies L, Welch HG. Increasing incidence of thyroid cancer in the United States, 1973-2002. JAMA. 2006;295(18):2164-2167.

2. Kilfoy BA, Zheng T, Holford TR, et al. International patterns and trends in thyroid cancer incidence, 1973-2002. Cancer Causes \& Control. 2009;20(5):525-531.

3. Rego-Iraeta A, Perez Mendez LF, Mantinan B, et al. Time trend for thyroid cancer in northwestern Spain: true rise in the incidence of micro and larger forms of papillary thyroid carcinoma. Thyroid. 2009;19(4):333-340. 
4. Roti E, degli Uberti EC, et al. Thyroid papillay microcarcinoma: a descriptive and meta-analysis study. Eur $J$ Endocrinol. 2008;159(6):659-673.

5. Hayward R. VOMIT (victims of modern imaging technology)-an acronym for our times. BMJ. 2003;326:1273.

6. Pazaitou-Panayoitou K, Capezzone M, Pacini F. Clinical features and therapeutic implications of papillary thyroid microcarcinoma. Thyroid. 2007;17(11):1085-1092.

7. Ito $\mathrm{Y}$, Uruno T, Nakano K, et al. An observation trial without surgical treatment in patients with papillary microcarcinoma of the thyroid. Thyroid. 2003;13(4):381-387.

8. Ito Y, Miyauchi A, Kihara M, et al. Patients age is significantly related to the progression of papillary microcarcinoma of thyroid under observation. Thyroid. 2014;24(1):27-34.

9. Hay ID, Hutchinson ME, Gonzalez-Losada T, et al. Papilary thyroid microcarcinoma: A study of 900 cases observed in a 60 -yer period. Surgery. 2008;144(6):980-988.

10. Lin JD, Kuo SF, Chao TC, et al. Incidental and nonincidental papillay thyroid microcarcinoma. Ann Surg Oncol. 15(8):2287-2292.

11. Mantinan B, Rego-Iraeta A, Larranaga A, et al. Factors influencing the outcome of patients with incidental papillary microcarcinoma. $J$ Thyroid Res. 2012:469397.

12. Choi SY, Park H, Kang MK, et al. The relationship between the $\mathrm{BRAF}^{\mathrm{v} 600 \mathrm{E}}$ mutation in papillary thyroid microcarcinoma and clinicopathologic factors. World J Surg Oncol. 2013;11:291.

13. Malandrino P, Pellegriti G, Attard M, et al. Papillary thyroid microcarcinoma: A comparative study of the characteristics and risk factors at presentation in two cancer registries. J Clin Endocrinol Metab. 2013;98(4):1427-1434.
14. Buffet C, Golmard JL, Hoang C, et al. Scoring system for predicting recurrences in patients with papillary thyroid microcarcinoma. Eur $J$ Endocrinol. 2012;167(2):267-275.

15. Rosai J, Li Volsi VA, Sobrinho-Simoes M, et al. Renaming papillary microcarcinoma of the thyroid gland: the Porto proposal. Int J Surg Pathol. 2003;11(4):249-251.

16. Durante C, Attard M, Torlontano M, et al. Identification and optimal postsurgical follow-up of patients with very low-risk papillay thyroid microcarcinomas. J Clin Endocrinol Metab. 2010;95(11):4882-4888.

17. Sugitani I, Toda K, Yamada K, et al. Three distinctly different kinds of papillary thyroid microcarcinoma should be recognized: our treatment strategies and outcomes. Word J Surg. 2010;34(6):1222-1231.

18. Cooper DS, Doherty GM, Haugen BR, et al. Revised American Thyroid Association management guidelines for patients with thyroid nodules and differentiated thyroid cancer. Thyroid. 2009;19(11):1167-1214.

19. Tuttle RM. Thyroid carcinoma. National Comprehensive Cancer Network (NCCN). 2012.

20. Pacini F, Schlumberger M, Dralle H, et al. European consensus for the management of patients with differentiated thyroid carcinoma of the follicular epithelium. Eur J Endocrinol. 2006;154(6):787-803.

21. Perros PP. British Thyroid Association. Royal College of Physicians. Guidelines for the management of thyroid cancer. ( $2^{\text {nd }}$ edn $)$, London: Royal College of Physicians, 2007.

22. Takami H, Ito $\mathrm{Y}$, Okamoto $\mathrm{T}$, et al. Therapeutic strategy for differentiated thyroid carcinoma in Japan base don a newly established guidelines managed by Japanese Society of Thyroid Surgeons and Japanese Association of Endocrine Surgeons. World J Surg. 2011;35(1):111-121.

23. Perros P, Colley S, Boelaert K, Guidelines for the Management of thyroid Cancer British Thyroid Association. Clin Endocrinol. 2000;81(Suppl 1):1-122. 